\title{
Thermal Decomposition of Some Chemotherapic Substances
}

\author{
Nedja Suely Fernandes, Marco Aurélio da Silva Carvalho Filho, \\ Roni Antônio Mendes, and Massao Ionashiro*
}

Instituto de Química, UNESP, C.P. 355, 14801-970 Araraquara - SP, Brazil

\begin{abstract}
Termogravimetria, termogravimetria derivada (TG,DTG), calorimetria exploratória diferencial (DSC) e difratometria de raios $\mathrm{X}$ foram utilizados para estudar o trimetroprim, sulfametoxazol, ampicilina, cloridrato de tetraciclina e rifampicina. Os resultados permitiram obter informações sobre a estabilidade térmica destes compostos e a decomposição térmica em atmosfera de ar.

Thermogravimetry, derivative thermogravimetry (TG, DTG), differential scanning calorimetry (DSC) and X ray diffraction powder patterns have been used to study trimethoprim, sulfamethoxazole, ampicillim, tetracycline hydrochloride and rifampim. The results revealed the extent of their thermal stability and also allowed interpretations concerning their thermal decompositions in air atmosphere.
\end{abstract}

Keywords: chemotherapic substances, thermal decomposition

\section{Introduction}

Several investigations have been carried out on the application of thermogravimetry (TG), differential thermal analysis (DTA) and differential scanning calorimetry (DSC) for the study of drug substances, excipients and drug substances in dosage forms. Montagut and coworkers ${ }^{1}$ investigated dipyrone by employing DTA and TG, and also examined the possibility of applying TG in quantitative studies. Wendlandt and Collins ${ }^{2}$ used DTA and TG thermal analysis techniques as aids in the characterization and identification of commercial non-preescription analgesics. Other investigations of the use of thermal analysis techniques for the study of drug substances and for applications in routine pharmaceutical analysis and in the pharmaceutical industry have also been described ${ }^{3-16}$. No reference has been found on the application of TG and DSC in the study of trimethoprim, sulfamethoxazole, ampicillim, tetracycline hydrochloride, rifampim and association of sulfamethoxazole with trimethoprim.

\section{Experimental}

Chemotherapic substances studied in this work, Fig. 1, were furnished by Nuplan-UFRN (Nucleo de Pesquisa em Alimentos e Medicamentos).

TG, DTG and DSC curves were obtained by using a Mettler TA-4000 thermal analysis system with an air flux of $150 \mathrm{~mL} \mathrm{~min}^{-1}$, a heating rate of $10{ }^{\circ} \mathrm{C} \mathrm{min}^{-1}$ and with a sample weight of $7 \mathrm{mg}$. An alumina crucible with a perforated cover was used for the DSC studies.
$\mathrm{X}$ ray powder patterns were obtained with an $\mathrm{HGZ}$ 4/B horizontal diffractometer (GDR) equipped with a proportional counter and pulse height discriminator. The BraggBrentano arrangement was adopted using $\mathrm{CuK} \alpha$ radiation $(\lambda=1.541 \AA)$ and a setting of $38 \mathrm{kV}$ and $20 \mathrm{~mA}$.

\section{Results and Discussion}

The $\mathrm{X}$ ray diffraction powder patterns, Fig. 2, show that the chemotherapic substances studied in this work are crystalline materials.

The TG and DTG curves of these chemotherapics, Fig. 3 , show mass losses in two or three consecutive steps, and indicated that the thermal stability based on the TG and DTG were as follows: trimethoprim > sulfamethoxazole $>$ tetracycline hydrochloride $>$ ampicilin $>$ rifampim.

The DSC curves, Fig. 4, show endothermic and exothermic peaks. For trimethoprim, Fig 4(a), the sharp endothermic peak at $203{ }^{\circ} \mathrm{C}$ is due to fusion and is in agreement with reference 17 . For sulfamethoxazole the sharp endothermic peak at $172{ }^{\circ} \mathrm{C}$ is due to fusion, and does not agreet with Ref. 17.

The TG and DTG curves, Fig. 3(a), show that trimethoprim is thermally stable up to $240^{\circ} \mathrm{C}$. The thermal decomposition observed in the TG and DTG curves occurs in two consecutive steps, between 240 and $700{ }^{\circ} \mathrm{C}$. The first mass loss up to $386{ }^{\circ} \mathrm{C}$ occurs through a fast process with mass loss of $42.92 \%$. The second mass loss begins with a slow process followed by a fast process, with mass loss of $57.0 \%$. 


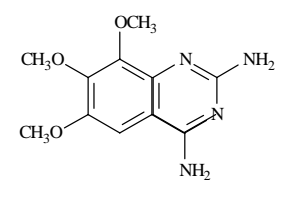

a) Trimethoprim

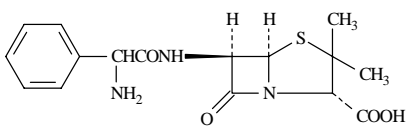

c) Ampicillim

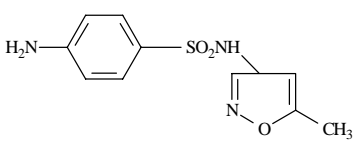

b) Sulfamethoxazole



d) Tetracycline hydrochloride

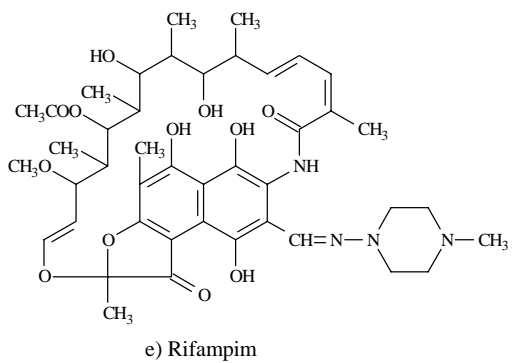

Figure 1. Some chemotherapic substances: (a) Trimethoprim, 5-[(3,4,5-trimethoxyphenyl) methyl]-2,4-pyrimidinediamine; (b) Sulfamethoxazole, 4-amino-N-(5-methyl-3-isoxazolyl) benzenesulfona-mide; (c) Ampicillim, 6-[(aminophenylacetyl) amino]-3,3-dimethyl-7-oxo-4-thia-1-azabicyclo [3.2.0] heptane-2-carboxylic acid; (d) Tetracycline hydrochloride, 4-(dimethylamino)-1,4,4a,5,5a,6-11,12a-octahydro-3,6,10,12, 12a-pentahy-droxy6-methyl-1,11-dioxo-2-naphthacene-carboxamide hydrochloride and (e) Rifampim, 3-[[(4-methyl-1-piperazinyl)imino]-methyl]rifamycin.

The DSC curve, Fig. 4(a), reveals endothermic and exothermic peaks. The endothermic peak at $203{ }^{\circ} \mathrm{C}$ is due to fusion and the exothermic peak at $310{ }^{\circ} \mathrm{C}$ is ascribed to oxidation of evolved products, corresponding to the first mass loss observed is the TG curve. The exothermic peak or exotherm between 550 and above $600{ }^{\circ} \mathrm{C}$ is attributed to the final thermal decomposition of the compound.

The TG and DTG curves of sulfamethoxazole, Fig.3(b), show mass losses in two steps between 205 and $700{ }^{\circ} \mathrm{C}$. A great similarity is observed in the TG and DTG curves of this compound with the curves of the trimethoprim. The first mass loss up to $346^{\circ} \mathrm{C}$ occurs with mass loss of $38.0 \%$, followed by the final thermal decomposition with mass loss of $61.9 \%$.

In the DSC curve of sulfamethoxazole, Fig. 4(b), the first endothermic peak at $172{ }^{\circ} \mathrm{C}$ is due to fusion. The exothermic peak at $270{ }^{\circ} \mathrm{C}$ and the exotherm between 380 and above $600{ }^{\circ} \mathrm{C}$ are ascribed to the oxidation of evolved products corresponding to the first mass loss observed in the TG curves, and final thermal decomposition of the compound, respectively.

The TG and DTG curves of ampicillim, Fig. 3(c), show mass losses in three consecutive steps between 190 and $670{ }^{\circ} \mathrm{C}$. The first step up to $225^{\circ} \mathrm{C}$, involving a mass loss of $28.3 \%$ and the second step $\left(225-300^{\circ} \mathrm{C}\right)$ with a mass loss of $22.1 \%$ are ascribed to the thermal decomposition of the compound, with formation of carbonaceous product. The last step $\left(300-670^{\circ} \mathrm{C}\right)$ is due to the final thermal decomposition of the carbonaceous product (49.4\%).

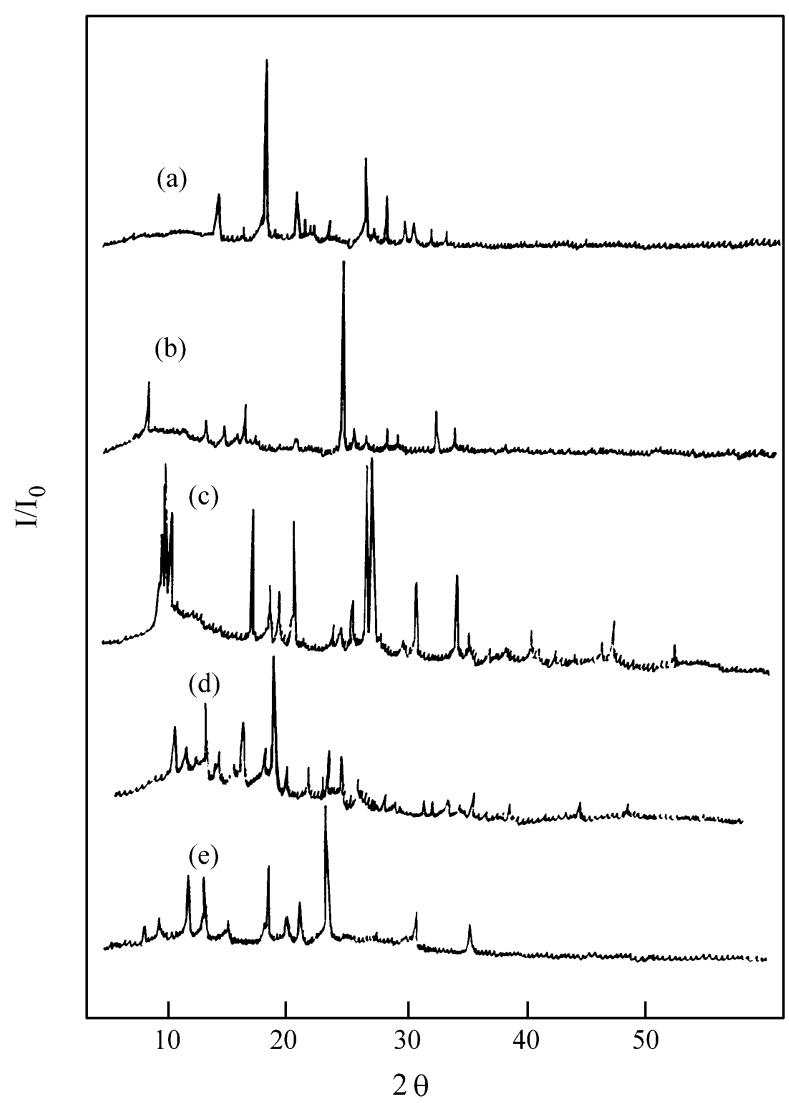

Figure 2. X-ray powder diffraction patterns of the chemotherapic substances: (a) trimethoprim; (b) sulfamethoxazole; (c) ampicillim; (d) tetracycline hydrochloride and (e) rifampim. 


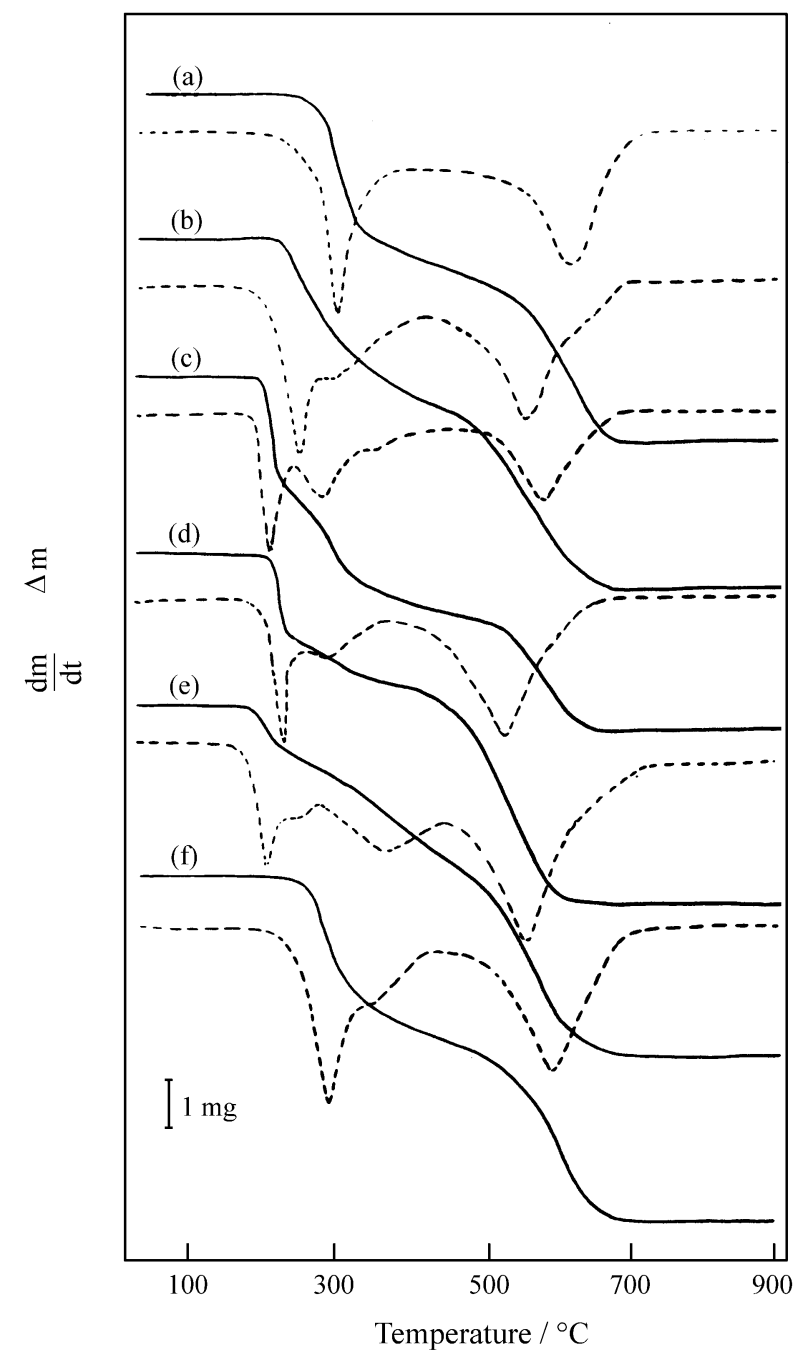

Figure 3. TG and DTG curves of the chemotherapic substances: (a) trimethoprim $(7.216 \mathrm{mg})$; (b) sulfamethoxazole (7.943 mg); (c) ampicil$\lim (7.593 \mathrm{mg})$; (d) tetracycline hydrochloride $(7.706 \mathrm{mg})$; (e) rifampim $(7.935 \mathrm{mg})$ and (f) trimethoprim-sulfamethoxazole $(8.187 \mathrm{mg})$.

In the DSC curve of ampicillim, Fig. 4(c), the sharp exothermic and endothermic peaks at $215{ }^{\circ} \mathrm{C}$ and $220{ }^{\circ} \mathrm{C}$ respectively, are ascribed to the oxidation-reduction reactions of the evolved products corresponding to the fist mass loss observed in the TG curves. The exotherm between 250 and $320^{\circ} \mathrm{C}$ and two small exothermic peaks at 350 and $380^{\circ} \mathrm{C}$ are attributed to the oxidation of the evolved products corresponding to the second mass loss of the TG curves.

The exotherm between 440 and above $600{ }^{\circ} \mathrm{C}$ is attributed to the final thermal decomposition of the compound.

For tetracycline hydrochloride, the TG and DTG curves, Fig. 3(d), show mass losses in three consecutive steps between 200 and $650{ }^{\circ} \mathrm{C}$. The first step up to $235^{\circ} \mathrm{C}$, a fast process with a mass loss of $20.3 \%$, and the second step $\left(235-350{ }^{\circ} \mathrm{C}\right)$ with a mass loss of $15.6 \%$ are ascribed to the thermal decomposition of the compound with forma-

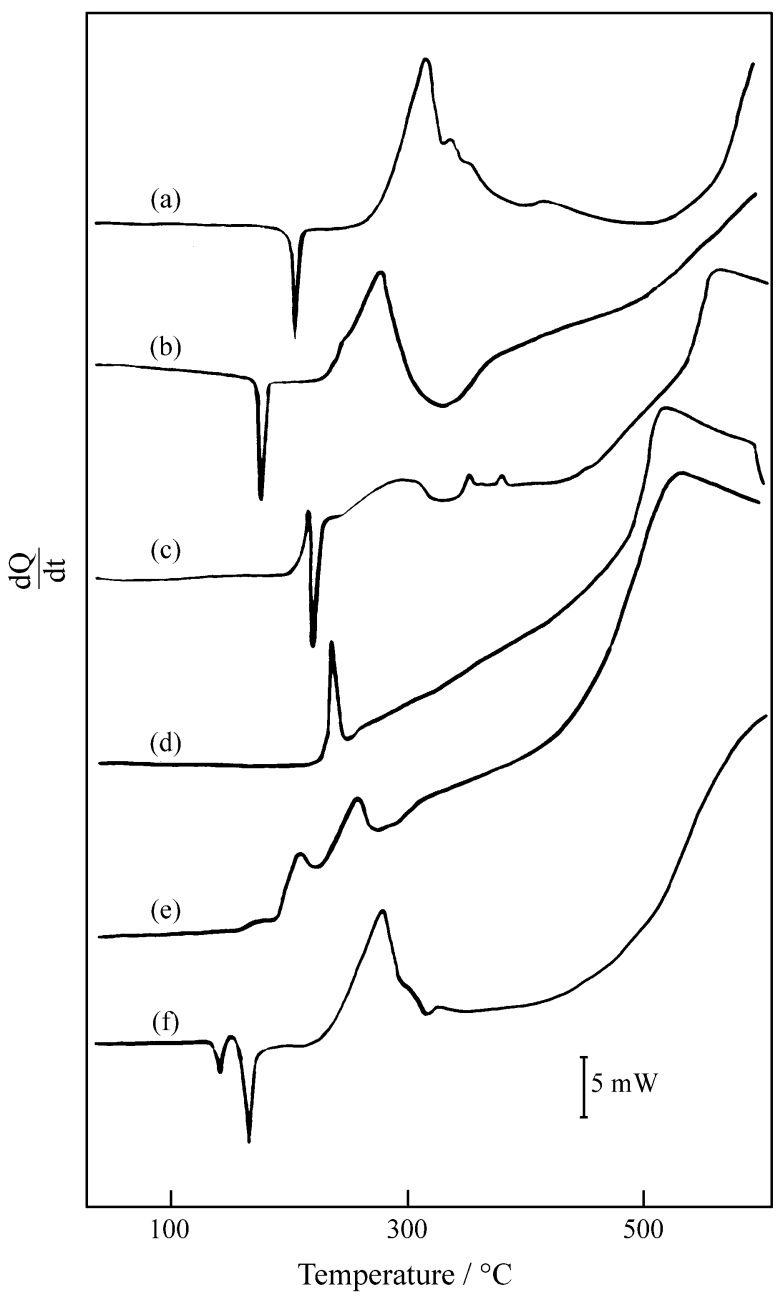

Figure 4. DSC curves of the chemotherapic substances: (a) trimethoprim (7.231 mg); (b) sulfamethoxazole (7.600 mg); (c) ampicillim (7.245 mg); (d) tetracycline hydrochloride $(7.481 \mathrm{mg})$; (e) rifampim $(7.551 \mathrm{mg})$ and (f) trimethoprim-sulfamethoxazole $(7.840 \mathrm{mg})$.

tion of carbonaceous product. The third step $\left(350-650^{\circ} \mathrm{C}\right)$ that begins with a slow process, followed by a fast process, which corresponds to a mass loss of $64.0 \%$, is attributed to the thermal decomposition of the carbonaceous product.

In the DSC curve of tetracycline hydrochloride, Fig. 4(d), the sharp exothermic peak at $235^{\circ} \mathrm{C}$ is attributed to the oxidation of the evolved products corresponding to the first mass loss observed in the TG curves. The exotherm between 250 and above $600{ }^{\circ} \mathrm{C}$ is ascribed to the thermal decomposition and pyrolysis of the carbonaceous product corresponding to the second and third mass losses of the TG curve.

The TG and DTG curves of rifampim, Fig. 3(e) show that the compound is thermally stable up to $185^{\circ} \mathrm{C}$; between 185 and $700{ }^{\circ} \mathrm{C}$, the TG curve suggests mass losses in two steps, whereas the DTG curve shows four consecutive steps. The first step between 185 and $225^{\circ} \mathrm{C}$, correspondisng to a mass loss of $10.9 \%$, is ascribed to the partial 
thermal decomposition of the compound. The second step between 225 and $700{ }^{\circ} \mathrm{C}$ shows that mass loss begins with a slow process, followed by a fast process with a mass loss of $88.7 \%$, which is ascribed to the final thermal decomposition of the compound.

The DSC curve of rifampim, Fig. 4(e) shows only exothermic peaks. The first and second exothermic peaks at 210 and $260{ }^{\circ} \mathrm{C}$ are ascribed to the partial thermal decomposition of the compound, corresponding to the first and second mass losses observed in the DTG curve. The exotherm between 280 and above $600{ }^{\circ} \mathrm{C}$ is ascribed to the thermal decomposition and pyrolysis of the carbonaceous product, corresponding to the third and fourth mass losses of the DTG curve.

The TG and DTG curves of the mixture, trimethoprimsulfamethoxazole (16.7\%-83.3\%), Fig. 3(f), show that the mixture is thermally stable up to $240^{\circ} \mathrm{C}$, i.e. that it exhibits same thermal stability as trimethoprim, despite the small quantity of this component in the mixture. The TG curve also shows that the thermal decomposition occurs in two consecutive steps, between 240 and $700{ }^{\circ} \mathrm{C}$, whereas the DTG curve suggest three steps, as observed for the TG and DTG curves of sulfamethoxazole. The mass loss observed up to $358{ }^{\circ} \mathrm{C}$ for the first step and between 358 and $700{ }^{\circ} \mathrm{C}$ for the second step, correspond to the losses of $38.7 \%$ and $60.7 \%$, respectively.

The DSC curve of the mixture, Fig. 4(f) show endothermic and exothermic peaks. The endothermic peaks at $140{ }^{\circ} \mathrm{C}$ and $165^{\circ} \mathrm{C}$ are due to fusion. The appearence of two fusion peaks at a temperature below that observed for each component, suggests a reaction provoked by the heating. The exothermic peak at $280{ }^{\circ} \mathrm{C}$ is ascribed to the oxidation of the evolved products corresponding to the first mass loss of TG curve. The exotherm between 320 and above $600{ }^{\circ} \mathrm{C}$ is ascribed to the thermal decomposition of the carbonaceous product corresponding to the last step of the TG curve.

\section{Conclusions}

The X-ray powder patterns verified that the chemotherapic substances studied in this work have a crystalline structure.

The TG, DTG and DSC curves provide information on the thermal stabilities and thermal decompositions of these compounds.

\section{Acknowledgements}

The authors thank FAPESP (Proc. 90/2932-4, and 97/01538-0) for finantial support, and Eider Araujo de Carvalho, NUPLAM Director, for supplying the chemotherapic substances used in this study and Rosemary Camargo Gabarron for aid in the preparation of this manuscript.

\section{References}

1. Montagut, M.; Codern, L.; Carulla, J. Afinidad 1963, 25,316 .

2. Wendlant, W.W.; Collins, L.W. Anal. Chim. Acta 1974, 71, 411 .

3. Margomenou-Leonipoulou, G.; Theodoratos, K.; Macris, G.G. Arch. Pharm. (Athens) 1974, 30, 100.

4. Domagalina, E.; Slawik, T. Acta Pol. Pharm. 1976, 33,623 .

5. Chauvet, A.;Masse, J. Trav. Soc. Pharm. Montpellier 1978, 38, 31 .

6. Radecki, A.; Wesolowski, M. J. Thermal Anal. 1979, 17,73 .

7. Wesolowski, M. Mikrochim. Acta 1980, 1, 199.

8. Wesolowski, M. Acta Pharm. Iugosl. 1982, 32, 303.

9. Martinez Recari, C.; Sanches Monge, J.M.; Perez de Ciriza, J.A.; Marcótegni, F. Rev. Asoc. Esp. Farm. Hosp. 1982, 6, 57.

10. Ager, D.J.; Alexander, K.S.; Bhatti, A.S.; Blackburn, J.S.; Dollimore, D.; Koogan, T.S.; Mooseman, K.A.; Muhvic, G.M.; Sims, B.; Webb, V.J. J. Pharm. Sci 1986, 75, 77.

11. Giron, D. J. Pharm. Biomed. Anal. 1986, 4, 755.

12. Gupchup, G.; Alexander, K.; Dollimore, D. Thermochim. Acta 1992, 196, 279.

13. Dwivedi, S.K.; Sattari, S.; Jamali, F.; Mitchell, A.G. Int J. Pharmaceutics 1992, 87, 95.

14. Ribeiro, Y.A.; de Oliveira, J.D.S.; Leles, M.I.G.; Juiz, S.A.; Ionashiro, M. J. Thermal Anal. 1996, 46, 1645.

15. Ribeiro, Y.A.; Caires, A.C.F.; Boralle, N.; Ionashiro, M. Thermochim. Acta 1996, 279, 177.

16. Valladão, D.M.S.; de Oliveira, L.C.S.; Zuanon Netto, J.; Ionashiro, M. J. Thermal Anal. 1996, 46, 1291.

17. The Merck Index, An Encyclopedia of Chemicals, Drugs and Biologicals, Merck \& Co, Inc Rohway, N.Y., USA, 11th ed, 1989, p. 1528, 1407.

Received: March 29, 1999

FAPESP helped in meeting the publication costs of this article 